\title{
EFFECTS OF SURFACE PREPARATION ON EPITAXIAL GAN ON 6H-SIC DEPOSITED VIA MOCVD
}

\author{
Z. Y. Xie*, C. H. Wei*, L. Y. Li*, J. H. Edgar*, J. Chaudhuri** ${ }^{* *}$ and C. Ignatiev ${ }^{* *}$ \\ *Department of Chemical Engineering, Kansas State University, Manhattan, KS 66506 \\ ** Department of Mechanical Engineering, Wichita State University, Wichita, KS 67208
}

Cite this article as: MRS Internet J. Nitride Semicond. Res. 4S1, G3.39(1999)

\begin{abstract}
A comparison was made of $6 \mathrm{H}-\mathrm{SiC}$ surfaces etched with $\mathrm{H}_{2}, \mathrm{C}_{2} \mathrm{H}_{4} / \mathrm{H}_{2}$, and $\mathrm{HCl} / \mathrm{H}_{2}$, and the resulting crystal quality of epitaxial $\mathrm{GaN}$ films deposited on these substrates. To remove the many fine scratches and to smooth the rough surfaces typical of commercial SiC substrates, the Si-face $6 \mathrm{H}-\mathrm{SiC}$ substrates were etched in $\mathrm{H}_{2}, \mathrm{C}_{2} \mathrm{H}_{4} / \mathrm{H}_{2}$, and $\mathrm{HCl} / \mathrm{H}_{2}$ at $1450{ }^{\circ} \mathrm{C}$. $\mathrm{GaN}$ was subsequently deposited on these etched surfaces after first depositing a low temperature GaN buffer layer via metalorganic chemical vapor deposition (MOCVD). The surface morphologies after etching and after GaN deposition were characterized by atomic force microscopy and Normaski differential interference contrast microscopy, while the crystal quality of the GaN films was assessed by double crystal x-ray rocking curves and x-ray topography. $6 \mathrm{H}-\mathrm{SiC}$ substrate surfaces were improved in terms of the removal of scratches and the reduction of surface roughness, and both surface morphology and crystal quality of the subsequently deposited GaN films were enhanced. However, the dislocation density was not decreased by the surface etching. The best $\mathrm{GaN}$ film was produced by etching the substrate in pure $\mathrm{H}_{2}$ for 40 minutes before growth. Recommendations for the optimum substrate treatment are made.
\end{abstract}

\section{INTRODUCTION}

$\mathrm{GaN}$ has long been a promising material for optoelectronic devices operating in the blue to ultra-violet region [1-2], but the lack of $\mathrm{GaN}$ bulk crystals hinders the improvement of $\mathrm{GaN}$ epitaxial film quality. Sapphire is the most common substrate for GaN epitaxy, but because of large differences in lattice constants(13.8\%) and thermal expansion coefficients(25.4\%), the threading dislocation density is typically high in the $\mathrm{GaN}$ film. In contrast, $6 \mathrm{H}-\mathrm{SiC}$ has a smaller lattice mismatch (3.5\%) with GaN, making it a better candidate for GaN growth [3].

High quality GaN was successfully deposited on $6 \mathrm{H}-\mathrm{SiC}$ substrates via MOCVD by several groups [4-6], but no detailed investigation of the effects of the $6 \mathrm{H}-\mathrm{SiC}$ substrate surface treatment prior to GaN growth has been reported. Compared to sapphire, the surface quality of commercial $6 \mathrm{H}-\mathrm{SiC}$ substrates is poor, containing various defects that may deteriorate the quality of epitaxial layer. Some defects, such as dislocations, and micropipes (holes approximately a micrometer in diameter) originate in the bulk of the substrate, while other defects such as ridges and scratches result from the lapping and polishing process. The later defects can be almost fully removed by etching the surface with hydrogen, with or without propane or $\mathrm{HCl}$ [7-8]. In the case of $\mathrm{SiC}$ epitaxy, defects in the film propagating from the substrate are minimized by in situ etching of substrates [7-8]. Furthermore, to avoid the formation of double position boundaries(DPB), 6H-SiC (off-axis) are etched and annealed to produce surface step heights corresponding to an integral multiple of the $6 \mathrm{H}-\mathrm{SiC}$ unit cell $(15 \AA)$ [9-10]. The effect of the substrate is expected to be similar for $\mathrm{GaN}$, hence, much attention should be given both to growth conditions and surface preparation of $6 \mathrm{H}-\mathrm{SiC}$ for $\mathrm{GaN}$ epitaxial growth. 
In this letter, we studied the etching of $6 \mathrm{H}-\mathrm{SiC}$ substrates using $\mathrm{H}_{2}, \mathrm{C}_{2} \mathrm{H} / \mathrm{H}_{2}$, and $\mathrm{HCl} / \mathrm{H}_{2}$ to remove scratches and pits. The quality of the substrtate surfaces thus produced were characterized, then GaN films were epitaxially deposited on these substrates. Finally, GaN films were examined, and a correlation between the surface treatment and film quality, both bulk structure and surface features, was developed.

\section{EXPERIMENT}

Substrate etching was performed in a cold-wall horizontal quartz reactor with an inside diameter of $50 \mathrm{~mm}$ operated at atmospheric pressure. The substrates were heated by a boron nitride coated graphite susceptor, and their temperature was measured both with an optical pyrometer and an R-type thermocouple, which were calibrated by the melting point of Si. The substrates were n-type, on-axis Si-face 6H-SiC (0001) wafers. Prior to etching, the substrates were ultrasonically degreased in organic solvents, dipped in $10 \% \mathrm{HF}$ acid, and rinsed in deionized water. The etching temperature was fixed at $1450{ }^{\circ} \mathrm{C}$ for all experiments, and the other experimental conditions were summarized in Table I.

Table I. Summary of on-axis Si-face 6H-SiC (0001) substrate etching conditions.

\begin{tabular}{|c|c|c|c|}
\hline Sample & Etching & Time (mins) & $\begin{array}{c}\text { FWHM of DCX } \\
(\operatorname{arcsec})\end{array}$ \\
\hline 1 & no treatment & N/A & 423 \\
\hline 2 & $\mathrm{H}_{2}$ etching & 10 & 395 \\
\hline 3 & $\mathrm{H}_{2}$ etching & 40 & 378 \\
\hline 4 & $100 \mathrm{ppm} \mathrm{C} \mathrm{H}_{4} / \mathrm{H}_{2}$ etching & 40 & 398 \\
\hline 5 & $0.5 \% \mathrm{HCl} / \mathrm{H}_{2}$ etching & 10 & 418 \\
\hline
\end{tabular}

The subsequent growth of GaN was performed in a vertical-type MOVPE reactor operated at low pressure (76 Torr). Before loading into the reactor, the etched substrates were also degreased and dipped in HF acid. Trimethylgallium (TMG) and ammonia $\left(\mathrm{NH}_{3}\right)$ were the $\mathrm{Ga}$ and $\mathrm{N}$ sources, and Pd-cell purified $\mathrm{H}_{2}$ was used as the carrier gas. The substrates in table I were loaded into the reactor simultaneously for one run, and preheated at $1100{ }^{\circ} \mathrm{C}$ for 10 minutes in $\mathrm{H}_{2}$ for surface cleaning using a rf induction heater. To compare the effects of substrate etching on the subsequent GaN growth, the experimental conditions were the same for each run, and all deposits had a $\mathrm{GaN}$ buffer layer deposited at $550{ }^{\circ} \mathrm{C}$.

The resulting etched $6 \mathrm{H}-\mathrm{SiC}$ surfaces and the final $\mathrm{GaN}$ films were characterized by Nomarski differential interference contrast microscopy (NDIC) and atomic force microscopy (AFM). The quality of the GaN films was assessed by X-ray double crystal rocking curves and X-ray double crystal topography.

\section{RESULTS AND DISCUSSION}

The AFM image of an as-received on-axis $\mathrm{Si}$-face $6 \mathrm{H}-\mathrm{SiC}$ substrate shows randomly oriented scratches, varying in depth and width (Fig. 1a). Some extreme scratches were broad $(\sim 200 \mathrm{~nm})$ and deep $(10 \mathrm{~nm})$, and disturbed the nucleation and surface morphology of the GaN film. Other defects such as micropipes and epitaxial pits were also observed (not shown). However, after etching 10 minutes in $\mathrm{H}_{2}$, the scratches began to disappear, and a periodic texture 
in one direction ([1-100]) of roughly parallel ridges formed as seen in Fig. 1b. The large shallow trench caused by a nonuniform etching rate on the (0001) surface at an early stage of etching. After etching for 40 minutes, the surface became smoother, and the scratches were completely removed (Fig. 1c). The terrace pattern was clear with a wider terrace (approximately $0.5 \mu \mathrm{m}$ ) than that $(0.2 \mu \mathrm{m})$ in Fig. 1b. The etching behavior of $\mathrm{C}_{2} \mathrm{H}_{4} / \mathrm{H}_{2}$ mixture was similar to the $\mathrm{H}_{2}$ with a slightly slower etch rate. The width and smoothness of the terraces from $\mathrm{C}_{2} \mathrm{H}_{4} / \mathrm{H}_{2}$ etching were narrower and rougher than those for $\mathrm{H}_{2}$ etching due to the low etching rate. Fig. 1d shows the surface after etching in $0.5 \% \mathrm{HCl} / \mathrm{H}_{2}$ for 10 minutes. Although the etch rate was higher, the residual scratches interrupted by terraces were still observed because of a short etching time. In terms of surface root mean square (RMS) values, the surface roughness was reduced from approximately $1.85 \mathrm{~nm}$ to below $1.0 \mathrm{~nm}$ for all etched $6 \mathrm{H}-\mathrm{SiC}$ surfaces with a best surface morphology for $\mathrm{H}_{2}$ etching for 40 minutes.

Our $6 \mathrm{H}-\mathrm{SiC}$ etching results were largely consistent with other groups $[8,11]$ with the exception that no well-defined straight step structure was observed, which we contributed to the low etching temperature. Nevertheless, most scratches were removed using the above etching method, and the improved surfaces were obtained.
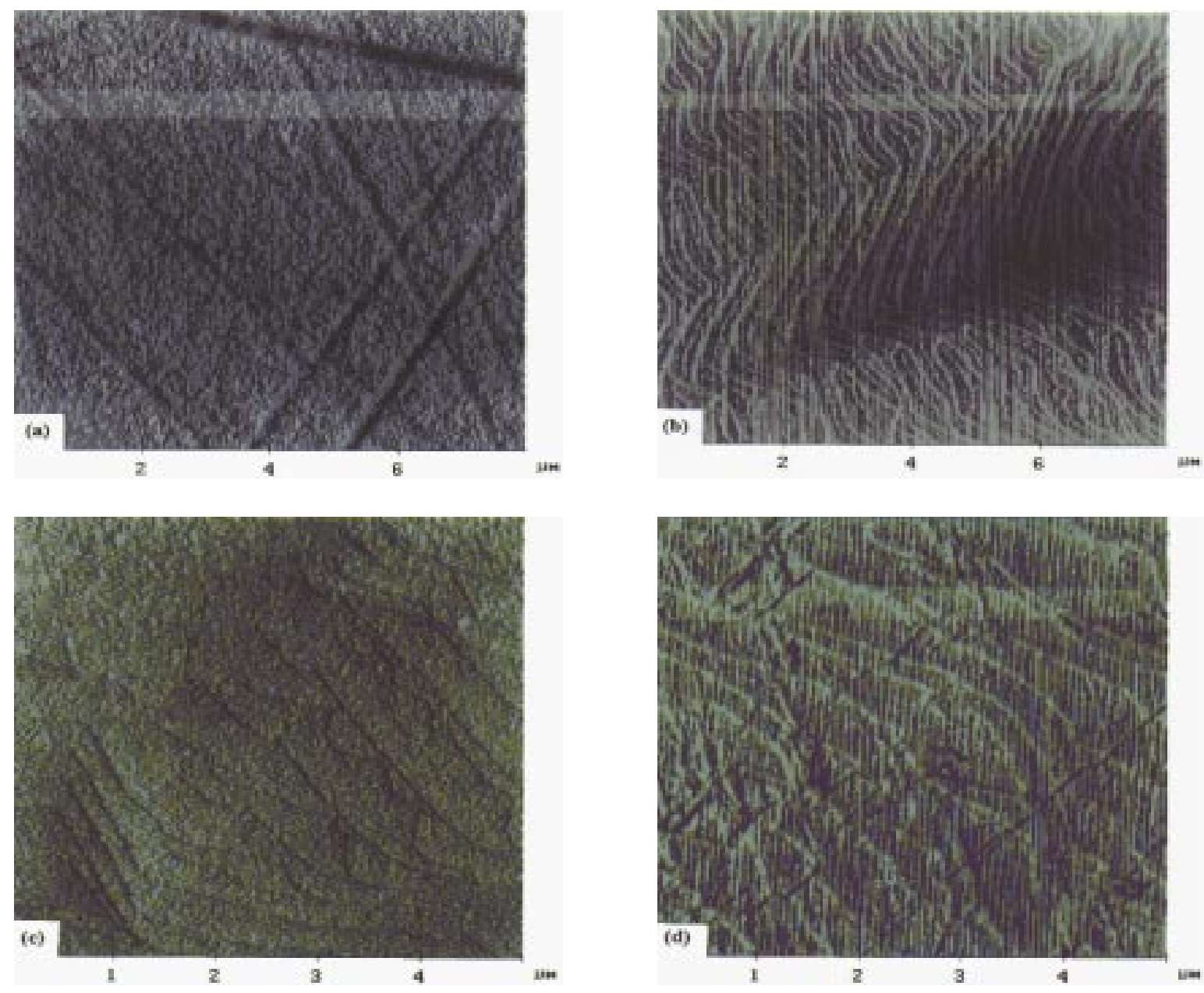

Figure 1. AFM images of 6H-SiC substrates, (a) as-received, no treatment, (b) after $\mathrm{H}_{2}$ etching for 10 mins, (c) after $\mathrm{H}_{2}$ etching for 40 mins, (d) after $0.5 \% \mathrm{HCl} / \mathrm{H}_{2}$ etching for 10 mins. 
The resulting GaN films had mirror-like surfaces as observed by the naked eye. However, some interesting features were illuminated by Normaski differential interference contrast microscopy. Fig $2 \mathrm{a}$ is the surface of the $\mathrm{GaN}$ film deposited on the untreated $6 \mathrm{H}-\mathrm{SiC}$ substrate. There is a high density of cracks, caused by the residual stress for the heteroepitaxial growth [12-13], between which very smooth GaN surfaces dominate. A relatively high density $\left(1.6 \times 10^{3} / \mathrm{cm}^{2}\right)$ of pits or pinholes (nominally $5 \mu \mathrm{m}$ in diameter) was mostly distributed along the cracks or at crack intersections. When $\mathrm{GaN}$ was deposited on the substrate etched by $\mathrm{H}_{2}$ for 40 minutes, the resulting GaN surface was similar to that in Fig. 2a, except that the density of pits decreased by a factor of four $\left(4.0 \times 10^{2} / \mathrm{cm}^{2}\right)$, and the pit diameter also decreased to $3 \mu \mathrm{m}$. Regardless of which etch was used, the density of pinholes was decreased compared to that of the untreated substrate surface.
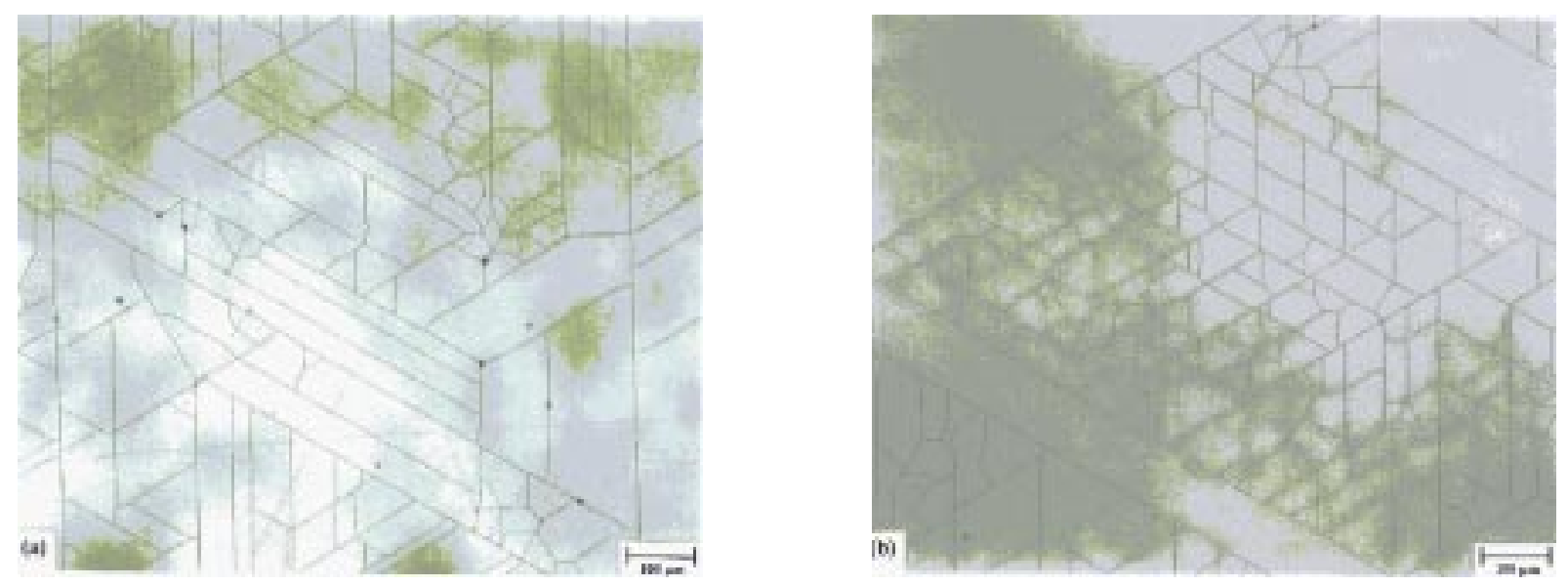

Figure 2. NDIC images of GaN films grown on $6 \mathrm{H}-\mathrm{SiC}$ substrates, (a) as-received, no treatment, (b) after $\mathrm{H}_{2}$ etching for 40 mins. Magnification: $200 \mathrm{X}$

What caused these pits? To answer this question, we compared our GaN surface morphologies with those obtained by other groups. Weeks et al. [5] deposited GaN thin films on vicinal and on-axis $6 \mathrm{H}-\mathrm{SiC}$ (0001) substrates using high temperature AlN buffer layers. Many small pits (nominally $30 \mathrm{~nm}$ in diameter) were observed, and the pit density was decreased by increasing the AlN deposition temperature. Random pinholes were also seen on the resulting $\mathrm{GaN}$ surfaces, and the density was decreased by increasing the GaN growth temperature. This phenomena was attributed to the possibly incomplete coalescence of GaN. Our observations were consistent with their results; however, the density of the pits increased when the $6 \mathrm{H}-\mathrm{SiC}$ substrate surface quality was poor. The density and size of pits were increased greatly $\left(5.3 \times 10^{3} / \mathrm{cm}^{2}\right.$ and $7.5 \mu \mathrm{m}$ in diameter respectively) when a high density of etch pits was intentionally introduced on the substrate surface after the etching of the $6 \mathrm{H}-\mathrm{SiC}$ substrate in $2 \%$ $\mathrm{HCl} / \mathrm{H}_{2}$ for 30 minutes at $1450{ }^{\circ} \mathrm{C}$. Therefore, the incomplete coalescence of $\mathrm{GaN}$ was attributed to the micropipes or deep pits originating on the $6 \mathrm{H}-\mathrm{SiC}$ substrate surface. GaN nucleation on these defects is difficult; if nucleation does occur, the GaN can not fill the defects, and leaves the GaN can not completely coalesce on these defects. Not only circular defects (pits or holes), but also wide and deep scratches can cause the incomplete coalescence of GaN films. Fig. 3a shows GaN surfaces separated by several deep and large scratches. The rough GaN surface was due to the unoptimized growth condition. The side walls of scratches on the $6 \mathrm{H}-\mathrm{SiC}$ substrates have different orientations, which results in low growth rate or growth direction not parallel to c-axis, compared to the growth on the basal plane of (0001). Sometimes, even shallow scratches 
disturbed the nucleation and growth of $\mathrm{GaN}$. As shown in Fig. 3b, the GaN growth pattern was disturbed by the scratches with concentrated steps grown along the scratches. The reason of the resulting pinholes on $\mathrm{GaN}$ films will be further studied and presented in another paper.
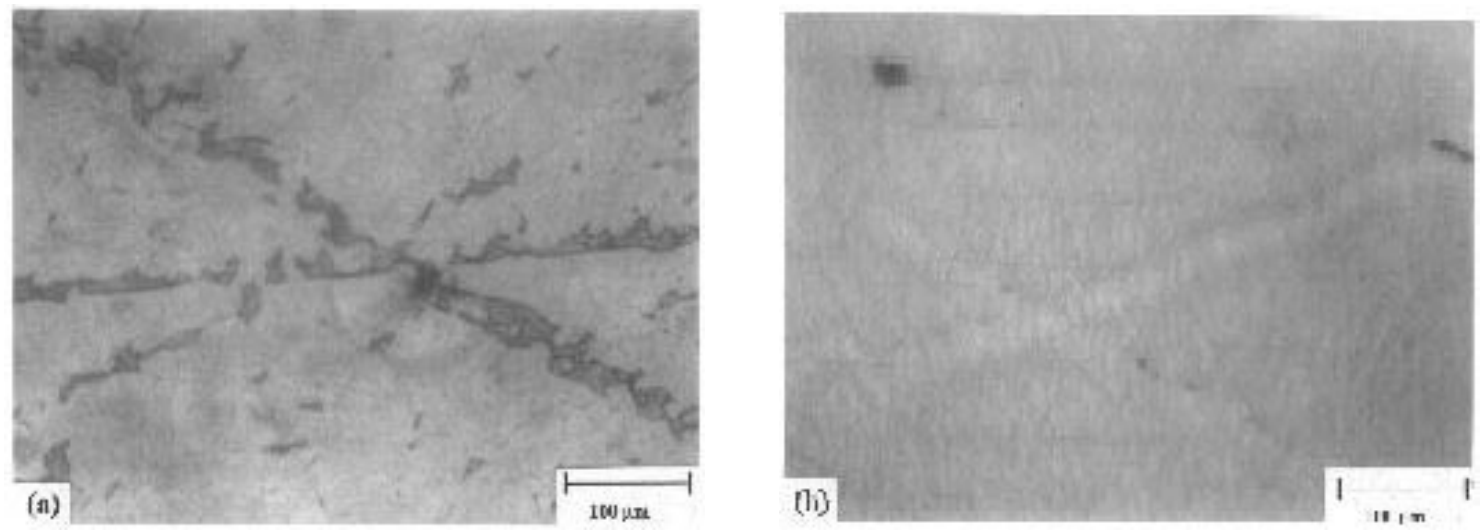

Figure 3. NDIC images of GaN film surfaces, (a) incomplete coalescence of GaN film separated by the substrate scratches, (b) the GaN film surface was disturbed by the scratches. Magnification: $400 X$.

Table I. displays the FWHM of the resulting GaN films deposited on the substrates etched at different conditions. The results are consistent with surface quality as evaluated by AFM. The FWHM of the GaN film grown on as-received substrate (sample1) had highest value, and thus the poorest crystal quality. The FWHM decreased with the increasing of $\mathrm{H}_{2}$ etching time (sample 2 and 3). The crystal quality of the GaN film deposited on sample 4 was between sample 2 and 3 due to the slower etching rate with the adding of $\mathrm{C}_{2} \mathrm{H}_{4}$. The last sample (sample 5) had a FWHM value close to sample 1, since the residual surface scratches were not completely removed. Although the FWHM has high values caused by unoptimized growth conditions, these values are comparable to each other because they were deposited in the same run. As a result, the $\mathrm{GaN}$ deposited on the 40 minute $\mathrm{H}_{2}$ etched substrate has the best quality, which is consistent with the AFM results.

An x-ray double crystal topograph was performed on sample 3. The reflection direction was [00.2]. The low angle grain boundaries were clearly identified to be repeated in the film. Linear defects were screw and mixed dislocations, which are common both in SiC substrates and $\mathrm{GaN}$ films. There is no evident difference between GaN samples deposited on untreated or etched $6 \mathrm{H}-\mathrm{SiC}$ substrates. Dislocation defects presents in the substrates would propagate into epitaxial film, and can not been removed by the etching method.

\section{CONCLUSIONS}

In summary, the as-received commercial $6 \mathrm{H}-\mathrm{SiC}$ substrates were etched using $\mathrm{H}_{2}$, $\mathrm{C}_{2} \mathrm{H}_{4} / \mathrm{H}_{2}$, and $\mathrm{HCl} / \mathrm{H}_{2}$ with a best surface improvement for the etching in $\mathrm{H}_{2}$ for 40 minutes. The surface morphologies of those samples deposited on the etched substrates improved in terms of the decreasing of the pinhole density. These pinholes and other defects were attributed to the scratches, micropipes, and pits originating on the as-received $6 \mathrm{H}-\mathrm{SiC}$ substrates. The crystal quality was increased as measured by DCX. However, the density of dislocation was not 
decreased by the substrate surface etching. The optimized etching condition is a 40-minute $\mathrm{H}_{2}$ etching at $1450{ }^{\circ} \mathrm{C}$ which was verified by the resulting $\mathrm{GaN}$ film surface morphology, and narrowing of FWHM of DCX. The improvement of GaN films in surface morphology and crystal quality is a direct result of the improved substrate surfaces. Therefore, the surface etching of $6 \mathrm{H}-\mathrm{SiC}$ is an effective way to improve the quality of $\mathrm{GaN}$ epitaxial films until the surface defects of as-received $6 \mathrm{H}-\mathrm{SiC}$ substrates are reduced.

\section{ACKNOWLEDGMENTS}

The authors gratefully acknowledge financial support by National Science Foundation (NSF) grant number DMR-9627333.

\section{REFERENCE}

1. G. Jacob, M. Boulou, and D. Bios, J. Lumin. 17, 263 (1978).

2. H. Amano, N. Sawaki, I. Akasaki, and Y. Toyoda, Appl. Phys. Lett. 48, 353 (1986).

3. M. E. Lin, B.Sverdlov, G. L. Zhou, and H. Morkoc, Appl. Phys. Lett. 62, 3479 (1993).

4. S. Tanaka, S. Iwai, and Y. Aoyagi, J. Cryst. Growth 170, 329 (1997).

5. T. W. Weeks Jr., M. D. Bremser, K. S. Ailey, E. Carlson, W. G. Perry, E. L. Piner, N. A. ElMasry, and R. F. Davis, J. Mater. Res. 11 (4), 1011 (1996).

6. C. F. Lin, H. C. Cheng, G. C. Chi, M. S. Feng, J. D. Guo, J. M. Hong, and C. Y. Chen, J. Appl. Phys. 82 (5), 2378 (1997).

7. J. A. Powell, D. J. Larkin, and P. B. Abel, J. Electron. Mater. 24, 295 (1995).

8. C. Hallin, F. Owman, P. Mårtensson, A. Ellison, A. Konstantinov, O. Kordina, and E. Janzén, J. Cryst. Growth, 181241 (1997).

9. F. Owman, C. Hallin, P. Mårtensson, and E. Janzén, J. Cryst. Growth 167, 391 (1996).

10. D. J. Smith, S.-C. Y. Tsen, B. N. Sverdlov, G. Martin, and H. Morkoc, Solid-State Elec. 41 (2), 349 (1997).

11. S. Karisson, and N. Nordell, Mater. Sci. Forum 264-268, 363 (1998).

12. K. Hiramatsu, T. Detchprohm, and I. Akasaki, Jpn. J. Appl. Phys. 32, 1528 (1993).

13. S. Nakamura, J. Cryst. Growth 170, 11 (1997). 